piles were being driven and an embankment of earth and weeds was being made, while at another point, much exposed to the force of the wind and water, a number of old grain junks had been drawn up in line against the bank to break the force of the waves.

THE just published Bulletin of the Société Normande de Géographie contains a note of some interest on Algeria, by M. E. Masqueray, whose address on the same subject is promised in the next number.

THE United States Government are about to despatch a party of military and naval engineers to examine the various routes proposed for an inter-oceanic ship canal across the Isthmus of Panama.

THE February number of Petermann's Mittheilungen contains two important papers on South American travel. Herr Fr. von Schenck describes a journey he made in 1878 in Antióquia, in the United States of Columbia, and another long paper gives an account of the travels of Messrs. Rogers and Ibar in SouthWest Patagonia in 1877 , to which are added the journals of $\mathrm{A}$. de Vicuna, in 1782 , and J. H. Gardiner in 1867.

WE have to record the death of M. Capitaine, the editor of L'Exploration, at the early age of forty. M. Capitaine had been in former years a surgeon in the national navy, and has written numerous papers on subjects of geographical interest.

\section{ON A NEW ACTION OF THE MAGNET ON ELECTRIC CURRENTS}

THE statement that "the mechanical force which urges a 1 conductor carrying a current across the lines of magnetic force, acts, not on the electric current, but on the conductor which carries it," has often been a puzzle to students of electricity. Experiments have been made at various times to prove that the statement is not correct, but have hitherto uniformly resulted in failure. Mr. E. H. Hall working under the direction of Prof. Rowland believes himself to have been more forlunate than his predecessors, and describes an experiment which apparently proves a permanent effect of a magnet on the distribution of currents in a system of wires, As Mr. Hall promises a more extended investigation we shall describe his experiment as much as possible in his own words without comment or criticism.

The following experiment had apparently been formerly tried by Prof. Rowland, but without success :-

"A disk or strip of metal, forming part of an electric current, was placed between the poles of an electro-magnet, the disk cutting across the lines of force. The two poles of a sensitive galvanometer were then placed in connection with different parts of the disk, through which an electric current was passing until two nearly equipotential points were found. The magnet current was then turned on and the galvanometer was observed, in order to detect any indication of a change in the relative potential of the two poles."

No such change could be observed and Mr. Hall now repeated the same experiment substituting a piece of gold leaf, mounted on glass to the metal strip. Experimenting as above he obtained on October 28 a decided deflection of the galvanometer needle.

"This deflection was much too large to be attributed to the direct action of the magnet on the galvanometer needle, or to any similar cause. It was moreover a permanent deflection and therefore not to be accounted for by induction."

Some rough quantitative experiments were tried with the result "that with a given form and arrangement of apparatus the action on the Thomson galvanometer is proportional to the product of the magnetic force by the current through the gold leaf. This is not the same as saying that the effect on the Thomson galvanometer is under all circumstances proportional to the current which is passing between the poles of the magnet. If a strip of copper of the same length and breadth as the gold leaf but $\frac{1}{4} \mathrm{~mm}$. in thickness is substituted for the latter the galvanometer fails to detect any current arising from the action of the magnet, except an induction current at the moment of making or breaking the magnet circuit."

A. S.

\section{UNIVERSITY AND EDUCATIONAL INTEL LIGENCE}

THERE will be an examination for at least one open scholarship in Queen's College, Oxford, on April 6 and following days.

$\simeq$ By E. H. Hall, Fellow of the Johns Hopkins University (American Foumal of Mathematics, vol. ii. p. 287 )
Papers will be set in Physics, Chemistry, and Biology (Comparative Anatomy and Physiology, the study of the Animal Kindom). No candidate will be expected to offer more than two of these subjects. There will also be a practical examination in one or more of the above subjects, if the examiners think it expedient. Candidates are requested to signify by letter to the Provost, not later than March $\mathrm{x}$, their intention of standing, and to state at the same time the subjects they propose to offer.

M. JULES FERRY has published a report stating that the deve. lopment of primary instruction in France has progressed in pro. portion to the subsidies made by the public treasury for this pur. pose, and which we noticed in one of our previous numbers. In the fifty years from 1827 to 1877 the number of public schools has been increased in the proportion of 100 to 175 , and the number of pupils from 103 to 182 .

\section{SCIENTIFIC SERIALS}

American Fournal of Science and Arts, January.-Prof. Stockwell here gives a detailed account of the principal periodic inequalities in the motions of the moon arising from the oblate. ness of the earth.- - Prof. Leconte contributes further ideas on the glycogenic function of the liver. He represents that waste tissue is not burned or changed into final products at once, but circulates as incombustible matter dissolved in the blood, is carried to the liver, and there prepared for final combustion and elimination. Only thereafter does it unite with $\mathrm{O}$ to form $\mathrm{CO}_{2}$ and $\mathrm{H}_{2} \mathrm{O}$.-Dr. Nichols proposes an optical method for measurement of high temperatures ; it corresponds to one of three methods proposed by M. Crova, who, however, ignored the serious practical difficulties, especially in the varying values of the emissive and absorptive capacity of different bodies.-The first results from a new diffraction-ruling engine (which appears to be a very perfect piece of work) are given by $\mathrm{Mr}$. Rogers. Mr. Hill's electrodynamometer for measuring large currents has been noticed in our columns, also Mr. Todd's observations on solar parallax from the velocity of light.-Mr. Levison describes certain curious electroly tic phenomena capable of exhibition to an audience.--Prof. Marsh describes new characters of Mosasauroid reptiles, Mr. Whitfield new fosšil crustaceans from the upper Devonian rocks of Ohio, and there are also geological papers on the Henry Mountains and the Wappinger Valley limestone.

Annalen der Physik und Chemie, No. 1.-Among the original matter in this number we note a chemical monograph of the mica-group, by Herr Rammelsberg; accounts of a new condensation or absorption-hygrometer, by Herr Matern, of some phenomena of phosphorescent light produced by electric discharges, by Herr E. Wiedemann, and of the phenomena, in polarised light, of a plate of magnesium platinum cyanide, cut at right angles to the optic axis, by Herr Lommel; a paper by Herr Korteweg, proving that, by the theory of dielectric polarisation, volume-changes of a dielectric body under the action of an electric force may be anticipated and calculated ; one by Herr Edlund, controverting Helmholtz's views as to the cause of electric currents produced in fow of liquids through tubes; and one by Herr Herwig, defending his conclusions regarding the electric conductivity of mercury vapour. We also note valuable papers (communicated to Academies) on the conductivity of iron for heat, by Herr G. Kirchhoff and Herr Hansemann ; on the differences of the two electric states, by Herr Mach and Herr Doubrava; and on a direct measurement of the work of induction, and a determination therefrom of the mechanical equivalent of heat, by Herr von Waltenhofen.

THE Fournal of Anatomy and Physiology, Normal and Pathological, vol. xiv., part 2., January.-Dr. A. H. Young, the intrinsic muscles of the marsupial hand (pl. 7), and on the myology of Viverra civetta.-Mr. W. R. Williams, the anatomy of the knee-joint.-Dr. D. J. Hamilton, development of fibrous tissue from the hepatic parenchyma in cirrhosis of the liver (pl. 8).-Dr. P. McBride, contributions to the pathology of the internal ear (pl. 9).-S. G. Shattock, a new bone in human anatomy, together with an investigation into the morphological significance of the so-called internal lateral ligament of the human lower jaw.-Dr. G. T. Beatson, the disease called sturdy in sheep, in its relation to cerebral localisation. - Dr. J. Carmichael, two cases of lesions of the temporo-sphenoidal lobe of the brain, with pathological examination by Dr. D. J. Hamilton (pl. 10$)$. - Dr. Osler, two cases of striated myo-sarcoma of the kidney.-Dr. G. A. Gibson, the sequence and duration of 